\title{
Cord Blood Theophylline Levels and Respiratory Morbidities in Preterm Infants
}

\author{
H. Tolga CELIK' ${ }^{1}$, Ayse KORKMAZ², Sule YIGIT², Murat YURDAKOK² \\ Ankara, Turkey
}

\begin{abstract}
OBJECTIVE: To investigate whether there is any relationship between cord blood theophylline levels and pulmonary morbidities in the early neonatal period in premature infants.

STUDY DESIGN: This prospective cohort study was conducted in Hacettepe University Hospital Neonatology Unit, between November 2010 and January 2012. Cord blood samples were collected at birth from premature infants, and theophylline levels were measured. Theophylline levels of cord blood were compared between infants with and without pulmonary morbidity.
\end{abstract}

RESULTS: A total of 90 infants (42 females, 48 males) were enrolled in the study. The mean gestational age was $31.1 \pm 3.1$ weeks, and the mean birth weight was $1527 \pm 540 \mathrm{~g}$. Early respiratory morbidities developed in 57 infants (63.3\%), while no respiratory morbidities were observed in 33 infants $(36.7 \%)$. There was no significant difference between the groups in blood gas parameters, oxygen saturation values and cord blood theophylline levels.

CONCLUSIONS: Although the theophylline levels that were measured in the cord blood were much lower than therapeutic serum levels, we concluded that the cord theophylline level is not valuable as a prognostic factor for pulmonary morbidities in premature newborns.

Keywords: Newborn, Neonate, Premature, Cord blood theophylline, Respiratory morbidities

Gynecol Obstet Reprod Med 2019;25(2):112-116

\section{Introduction}

Caffeine and theophylline are widely used drugs in the treatment of apnea of prematurity. As respiratory stimulants, they are also used to weaning from mechanical ventilation (1, 2 ). These drugs and their precursors are taken in via certain daily foods. Methylxanthines such as caffeine and its metabolites (paraxanthine, theophylline, and theobromine) are available in tea, coffee, cocoa, cola, and chocolate $(3,4)$. Plasma

${ }^{1}$ Hacettepe University Faculty of Medicine Department of Pediatrics Division of Neonatology, Ankara, Turkey

${ }^{2}$ Hacettepe University Faculty of Medicine Department of Pediatrics Division of Neonatology, Ankara, Turkey

Address of Correspondence: H. Tolga Celik

Hacettepe University, Faculty of Medicine Department of Pediatrics, Division of Neonatology, 06100 Sihhiye Altındağ Ankara / Turkey htcelik@gmail.com

Submitted for Publication: 08. 11.2018

Accepted for Publication:

12. 03.2019

ORCID IDs of the authors:

T.Ç.: 0000-0002-1725-0722, A.K.:0000-0003-4934-1124

S.Y.: 0000-0002-8755-0384, M.Y.:0000-0002-6890-9224

\begin{tabular}{|c|c|}
\hline \multirow{3}{*}{ 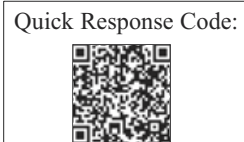 } & Access this article online \\
\hline & $\begin{array}{l}\text { Website: www.gorm.com.tr } \\
\text { e- mail: info@gorm.com.tr }\end{array}$ \\
\hline & DOI:10.21613/GORM.2018.856 \\
\hline
\end{tabular}

How to cite this article: Celik HT. Korkmaz A. Yigit S. Yurdakok M. Cord Blood Theophylline Levels and Respiratory Morbidities in Preterm Infants. Gynecol Obstet Reprod Med 2019;25(2):112-116 levels of methylxanthines vary, depending on the amount of their consumption in the daily diet (5). Methylxanthines are rapidly and completely absorbed from the gastrointestinal tract and penetrate all tissues, including blood-brain and placenta barriers $(1,2)$. Caffeine is mainly metabolized by the cytochrome P450 1A2 (CYP1A2), and another enzyme that regulates the metabolism to a lesser extent is $\mathrm{N}$-acetyltransferase $(2,6)$. Since activities of both these enzymes decrease during pregnancy, concentrations of caffeine gradually increase, leading to an accumulation of caffeine in the mother and fetus (2). Caffeine and its metabolites, such as paraxanthine, theophylline and theobromine, easily pass fetal circulation via the placenta. There are no significant differences in plasma levels of theophylline between the maternal and fetal circulations (2). However, it is not known what effects caffeine and its metabolites, which are taken through the maternal diet during the fetal period, have on the respiratory system in the early neonatal period.

In this study, we aimed to investigate whether there is any relationship between cord blood theophylline levels and pulmonary morbidities in the early neonatal period in premature infants.

\section{Material and Method}

This prospective cohort study was conducted in Hacettepe University Hospital Neonatology Unit, between November 2010 and January 2012. The study protocol was approved by 
the institutional ethical committee. After parental informed consent, cord blood samples were collected at birth from premature infants whose gestational ages were under 37 weeks, and theophylline levels were measured. Infants with congenital anomalies and chromosomal disorders were excluded from the study. Cord blood samples $(1 \mathrm{~mL})$ were taken from the infants. Sera of blood samples were separated and theophylline levels were measured in $\mu \mathrm{g} / \mathrm{ml}$, using the ultraviolet spectrophotometric method. Pulmonary morbidities occurring in the first week of life in infants, such as transient tachypnea of newborn (more than 60 breaths per minute, less than 24 hours), respiratory distress syndrome (RDS, defined as respiratory findings, typical radiological findings, oxygen or mechanical ventilation requirement, surfactant requirement), apnea (defined as cessation of breathing for more than 20 seconds, or a shorter respiratory pause associated with oxygen desaturation and/or bradycardia), congenital pneumonia, and the requirement of ventilation with positive pressure etc., were recorded. Theophylline levels of cord blood were compared between infants with and without pulmonary morbidity. The Helsinki Declaration rules were complied with during this study.

PASW 18 for Windows (Chicago, USA) was used for the statistical analysis. Normally distributed variables were evalu- ated by parametric tests, while non-normally distributed variables were evaluated by non-parametric tests. Categorical and qualitative variables were analyzed by $\chi^{2}$ test and Fisher's exact $\chi^{2}$ test. $P$ value $<0.05$ were considered statistically significant.

\section{Results}

A total of 90 infants (42 females, 48 males) were enrolled in the study. The mean gestational age was $31.1 \pm 3.1$ weeks (range: 24-36 weeks), and the mean birth weight was $1527 \pm 540 \mathrm{~g}$ (range: $530-2810 \mathrm{~g}$ ). Early respiratory morbidities developed in 57 infants (Group 1, 63.3\%), while no respiratory morbidities were observed in 33 infants (Group 2, 36.7\%). Although mean cord blood theophylline levels were lower in Group $1(0.22 \pm 0.17 \mu \mathrm{g} / \mathrm{mL})$ than Group $2(0.23 \pm 0.29 \mu \mathrm{g} / \mathrm{mL})$, this difference was not statistically significant $(p=0.531)$. Table I shows the comparison of cord blood theophylline levels between the subgroups created according to the neonatal features and respiratory parameters. There was no significant difference in blood gas parameters, oxygen saturation values, the incidence of RDS, the need of mechanical ventilation in the first 48 hours, duration of mechanical ventilation and oxygen support, the incidence of apnea, postnatal age of introducing methylxanthine (caffeine or theophylline) treatment, duration of hospi-

Table I: Comparison of demographic, neonatal and clinical features of infants with or without respiratory distress

\begin{tabular}{|c|c|c|c|}
\hline (Infants & $\begin{array}{l}\text { Group 1a } \\
\text { with respiratory distress) } \\
(n=57)\end{array}$ & $\begin{array}{c}\text { Group 2a } \\
\text { (Infants without respiratory distress) } \\
(\mathrm{n}=33)\end{array}$ & $p$ \\
\hline Gestational age (week) $)^{* *}$ & $29.6 \pm 2.7$ & $33.8 \pm 1.6$ & .000 \\
\hline Birth weight $(g)^{* *}$ & $1275 \pm 469$ & $1961 \pm 343$ & .000 \\
\hline Gender (M/F), n (\%) & $29(50.9) / 28(49.1)$ & $19(57.6) / 14(42.4)$ & .539 \\
\hline SGA, n (\%) & $16(28.1)$ & $10(30.3)$ & .822 \\
\hline Antenatal steroid, $\mathrm{n}(\%)$ & $24(42.1)$ & $9(27.3)$ & .160 \\
\hline Maternal age $(\text { year })^{\star *}$ & $30.1 \pm 5.4$ & $29.9 \pm 4.8$ & .887 \\
\hline Maternal preeclampsia, n (\%) & $14(24.6)$ & $2(6.1)$ & .027 \\
\hline Type of delivery (NSVD/CS), n (\%) & $4(7.0) / 53(93.0)$ & $0(0) / 33(100)$ & .292 \\
\hline Apgar score (5th $\min )^{*}$ & $7(5-10)$ & $9(6-10)$ & .000 \\
\hline Resuscitation at birth, $\mathrm{n}(\%)$ & $36(63.2)$ & $2(6.1)$ & .000 \\
\hline Cord blood $\mathrm{pH}^{* *}$ & $7.27 \pm 0.08$ & $7.22 \pm 0.11$ & .216 \\
\hline Apnea, n (\%) & 25 (43.9) & $0(0)$ & - \\
\hline RDS, n (\%) & $36(63.2)$ & $0(0)$ & - \\
\hline TTN, n (\%) & $2(3.5)$ & $0(0)$ & - \\
\hline Pneumonia, n (\%) & $18(31.6)$ & $1(3.0)$ & .001 \\
\hline BPD, n (\%) & $10(17.5)$ & $0(0)$ & - \\
\hline PDA, n (\%) & $27(47.4)$ & $0(0)$ & - \\
\hline Sepsis, n (\%) & $25(43.9)$ & $1(3.0)$ & .000 \\
\hline \multicolumn{3}{|l|}{ Mechanical ventilation support, } & - \\
\hline Duration of hospitalization (day) ${ }^{*}$ & $20(2-81)$ & $7(3-22)$ & .000 \\
\hline Mortality, n (\%) & $12(21.1)$ & $0(0)$ & - \\
\hline Cord blood theophylline levels $(\mu \mathrm{g} / \mathrm{ml})^{* *}$ & $0.22 \pm 0.17$ & $0.23 \pm 0.29$ & .531 \\
\hline Infants with cord blood theophylline levels of zero, $\mathrm{n}(\%)$ & $14(24.6)$ & $15(45.5)$ & .041 \\
\hline
\end{tabular}

${ }^{*}$ median (minimum-maximum), ${ }^{* *}$ mean $\pm S D$ (standard deviation)

BPD: Bronchopulmonary dysplasia, PDA: Patent ductus arteriosus, RDS: Respiratory distress syndrome, SGA: Small for gestational age, NSVD: Normal spontaneous vaginal delivery, CS: Cesarean section, TTN: Transient tachypnea of the newborn. 
talization, and cord blood theophylline levels. In the study group, theophylline level in the cord blood of 29 infants was 0. Between this group and the remaining 61 infants, there was no significant difference in respiratory morbidities.

All infants with and without respiratory problems were matched according to similar gestational ages, forming two new subgroups (Group $1 \mathrm{~b}[\mathrm{n}=20]$, Group $2 \mathrm{~b}[\mathrm{n}=20]$ ); no significant difference in cord blood theophylline levels was detected between these two subgroups. The comparison of the demographic, neonatal and clinical features of infants with or without respiratory distress in the new subgroups formed according to similar gestational ages is shown in table II.

In the study group, theophylline was present in the cord blood of 61 infants (Group 2c), while it was absent in the other 29 infants (Group 1c). We found no significant difference between the two new groups with respect to the demographic, neonatal and clinical features of infants, except for respiratory distress. Surprisingly, respiratory distress was significantly higher in Group 2c than Group 1c. Table III shows the comparison of the demographic, neonatal and clinical features of infants with or without respiratory distress in subgroups created according to the presence or not of theophylline in the cord blood.

\section{Discussion}

In this prospective observational study, we showed that there is no relationship between cord blood theophylline levels and pulmonary morbidities in the early neonatal period in premature infants. In every period of pregnancy, methylxanthines can pass easily through the placenta, and can reach maternal levels in infants. Both the fetus and placenta lack the enzymes needed to metabolize methylxanthines, and therefore, elimination in the fetus is almost entirely dependent upon renal excretion without any change in their composition (2). The enzyme activity of CYP1A2 reaches the adult level only in the postnatal $3^{\text {rd }}-8^{\text {th }}$ month. Consequently, half-lives of methylxanthines are longer in newborns than adults (theophylline 20-30 hours, caffeine 40-230 hours). The chemical composition of theophylline, its effect mechanism and biological effects are similar to those of caffeine $(1,2)$. Furthermore, some amount of theophylline is converted to caffeine via back-methylation reaction. The obvious effect of methylxanthines may be the same, since caffeine and theophylline exert similar biologic actions. The half-life of theophylline in premature infants is 20 30 hours. Therapeutic blood levels of methylxanthines are 5-25 $\mathrm{mg} / \mathrm{L}$ for caffeine and $6-12 \mathrm{mg} / \mathrm{L}$ for theophylline $(1,2)$. In studies conducted on animals, it was reported that the use of maternal aminophylline increases the levels of phospholipid in fetal lungs $(7,8)$, while in premature infants, treatment with postnatal caffeine and theophylline improves pulmonary outcomes, reduces the risk of bronchopulmonary dysplasia and has beneficial effects on cognitive outcomes $(1,2)$.

Table II: Comparison of demographic, neonatal and clinical features of infants with or without respiratory distress in new subgroups created according to similar gestational ages

\begin{tabular}{|c|c|c|c|}
\hline & $\begin{array}{c}\text { Group 1b } \\
\text { (Infants with respiratory distress) } \\
(\mathrm{n}=20)\end{array}$ & $\begin{array}{l}\text { Group } 2 b \\
\text { (Infants without respiratory distress) } \\
\qquad(\mathrm{n}=20)\end{array}$ & $p$ \\
\hline Gestational age (week) $)^{* *}$ & $32.4 \pm 1.3$ & $33.1 \pm 1.1$ & .051 \\
\hline Birth weight $(\mathrm{g})^{* *}$ & $1708 \pm 445$ & $1912 \pm 328$ & .107 \\
\hline Gender (M/F), n (\%) & $12(60.0) / 8(40.0)$ & $13(65.0) / 7(35.0)$ & .744 \\
\hline SGA, n (\%) & $3(15)$ & $5(25)$ & .429 \\
\hline Antenatal steroid, n (\%) & $8(40.0)$ & $10(50.0)$ & .357 \\
\hline Maternal age $(\text { year })^{* *}$ & $29.7 \pm 5.0$ & $29.5 \pm 4.9$ & .900 \\
\hline Maternal preeclampsia, n (\%) & $2(10)$ & $5(25)$ & .212 \\
\hline Type of delivery (NSVD/CS), $n$ (\%) & $0(0) / 20(100)$ & $0(0) / 20(100)$ & - \\
\hline Apgar score $\left(5^{\text {th }} \min \right)^{*}$ & $7(5-10)$ & $9(8-10)$ & .000 \\
\hline Resuscitation at birth, $\mathrm{n}(\%)$ & $11(55.0)$ & $1(5.0)$ & .001 \\
\hline Cord blood $\mathrm{pH}^{* *}$ & $7.27 \pm 0.06$ & $7.28 \pm 0.09$ & .924 \\
\hline Apnea, n (\%) & $3(15.0)$ & $0(0)$ & - \\
\hline RDS, n (\%) & $10(50.0)$ & $0(0)$ & - \\
\hline TTN, n (\%) & $1(5)$ & $0(0)$ & - \\
\hline Pneumonia, n (\%) & $3(15.0)$ & $1(5.0)$ & .292 \\
\hline BPD, n (\%) & $1(5)$ & $0(0)$ & - \\
\hline PDA, n (\%) & $4(20)$ & $0(0)$ & - \\
\hline Sepsis, n (\%) & $3(15.0)$ & $1(5.0)$ & .292 \\
\hline Duration of hospitalization (day) ${ }^{*}$ & $14(5-79)$ & $8(4-22)$ & .010 \\
\hline Mortality, n (\%) & $0(0)$ & $0(0)$ & - \\
\hline Cord blood theophylline levels $(\mu \mathrm{g} / \mathrm{mL})^{\star *}$ & $0.22 \pm 0.16$ & $0.26 \pm 0.32$ & .698 \\
\hline Infants with cord blood theophylline levels & $5(25.0)$ & $8(40.0)$ & .311 \\
\hline
\end{tabular}

BPD: Bronchopulmonary dysplasia, PDA: Patent ductus arteriosus, RDS: Respiratory distress syndrome, SGA: Small for gestational age, NSVD: Normal spontaneous vaginal delivery, CS: Cesarean section, TTN: Transient tachypnea of the newborn 
A significant teratogenic effect of caffeine and theophylline intake has not been detected in epidemiologic studies in humans $(9,10)$. Some epidemiological studies have shown that excessive maternal consumption of caffeine in humans (more than $>300 \mathrm{mg} /$ day) may be related to reduced fertility and may increase the risk of spontaneous abortions, intrauterine growth restriction and stillbirth (11-19). On the other hand, major effects of caffeine on fetal growth restriction, low birth weight and preterm delivery have not been shown in several prospective epidemiologic studies (15). There have been a few studies on the perinatal outcomes in newborns of mothers treated with theophylline, but no relation between theophylline and low birth weight and prematurity were found $(2,6,10)$. In our study, determining the exact amount of food containing methylxanthines in the daily diets of the mothers was not possible. Furthermore, since methylxanthine levels are the same in each mother and her infant, only the infants' cord blood methylxanthine levels were studied. Caffeine and its primary metabolites, paraxanthine, theobromine, and theophylline, are detectable in all body fluids and in the umbilical cord blood $(5,6)$. However, until the present study, there had been no study investigating the relationship between cord blood theophylline levels and respiratory morbidities in the early neonatal period in premature infants. In this study, mean cord blood theophylline levels were determined as $0.23 \pm 0.22 \mu \mathrm{g} / \mathrm{mL}$.

The amount of methylxanthines that passes from mother to infant depends on the mother's diet. Consumption of beverage contains caffeine (especially coffee, cola etc.) and chocolate is higher in developed countries (3-5). In our country, it is thought that these kinds of foods and drinks are consumed to a lesser extent for cultural reasons. Since a questionnaire assessment of methylxanthine exposure does not provide an accurate measurement of maternal or fetal dose and since there are no differences between maternal and fetal methylxanthine levels, we measured cord blood theophylline levels.

In the study group, theophylline level in the cord blood of $29(32.2 \%)$ infants was 0. Between this group (29 infants, Group 1c) and the remaining infants [61 infants $(67.8 \%)$, Group 2c], there was no significant difference in blood gas parameters, oxygen saturation values, the incidence of RDS, need of mechanical ventilation in the first 48 hours, duration of mechanical ventilation and oxygen support, the incidence of apnea, postnatal age of introducing methylxanthine (caffeine or theophylline) treatment, and duration of hospitalization. However, respiratory distress was significantly higher in

Table III: Comparison of demographic, neonatal and clinical features of infants with or without respiratory distress in subgroups created according to theophylline availability in the cord blood

\begin{tabular}{|c|c|c|c|}
\hline & $\begin{array}{l}\text { Group 1c } \\
\text { heophylline absent in cord blood } \\
(\mathrm{n}=29)\end{array}$ & $\begin{array}{l}\text { Group } 2 \mathrm{c} \\
\text { Theophylline present in cord blood } \\
\qquad(\mathrm{n}=61)\end{array}$ & $p$ \\
\hline Gestational age (week) $)^{\star \star}$ & $31.8 \pm 2.7$ & $30.8 \pm 3.2$ & .219 \\
\hline Birth weight $(g)^{* *}$ & $1630 \pm 480$ & $1478 \pm 563$ & .211 \\
\hline Gender (M/F), n (\%) & $13(44.8) / 16(55.2)$ & $35(57.4) / 26(42.6)$ & .265 \\
\hline SGA, n (\%) & $8(27.6)$ & $18(29.5)$ & .851 \\
\hline Single/Twins, n (\%) & $16(55.2) / 13(44.8)$ & $36(59.0) /(41.0)$ & .730 \\
\hline Antenatal steroid, $\mathrm{n}(\%)$ & $7(24.1)$ & $26(42.6)$ & .214 \\
\hline Maternal age (year) $)^{\star *}$ & $30.3 \pm 4.8$ & $29.9 \pm 5.4$ & .674 \\
\hline Maternal preeclampsia, n (\%) & $4(13.8)$ & $12(19.7)$ & .495 \\
\hline Type of delivery (NSVD/CS), n (\%) & $0(0) / 29(100)$ & $4(6.6) / 57(93.4)$ & .301 \\
\hline Doppler abnormality, n (\%) & $5(17.4)$ & $10(16.4)$ & 1.000 \\
\hline Apgar score $\left(5^{\text {th }} \min \right)^{*}$ & $9(5-10)$ & $8(5-10)$ & .028 \\
\hline Resuscitation at birth, $\mathrm{n}(\%)$ & $8(27.6)$ & $30(49.2)$ & .053 \\
\hline Cord blood $\mathrm{pH}^{* *}$ & $7.22 \pm 0.09$ & $7.23 \pm 0.11$ & .304 \\
\hline Respiratory distress, n (\%) & $14(48.3)$ & $43(70.5)$ & .041 \\
\hline Apnea, n (\%) & $8(27.6)$ & $17(27.9)$ & .978 \\
\hline RDS, n (\%) & $10(34.5)$ & $26(42.6)$ & .461 \\
\hline TTN, n (\%) & $0(0)$ & $2(3.3)$ & - \\
\hline Pneumonia, n (\%) & $5(17.2)$ & $14(23.0)$ & .535 \\
\hline BPD, n (\%) & $3(10.3)$ & $7(11.5)$ & 1.000 \\
\hline PDA, n (\%) & $5(17.2)$ & $22(36.1)$ & .069 \\
\hline Sepsis, $n(\%)$ & $7(24.1)$ & $19(31.1)$ & .493 \\
\hline Mechanical ventilation support in first 48 hours, $n(\%)$ & $16(55.2)$ & $42(68.9)$ & .205 \\
\hline Duration of hospitalization (day) ${ }^{*}$ & $13(3-79)$ & $14(2-81)$ & .752 \\
\hline Mortality, n (\%) & $0(0)$ & $12(19.7)$ & .008 \\
\hline
\end{tabular}

BPD: Bronchopulmonary dysplasia, PDA: Patent ductus arteriosus, RDS: Respiratory distress syndrome, SGA: Small for gestational age, NSVD: Normal spontaneous vaginal delivery, CS: Cesarean section, TTN: Transient tachypnea of the newborn. 
Group 2c than Group 1c. This result may suggest that low levels of cord blood theophylline might not affect the early respiratory morbidities in premature infants.

In a few experimental studies, it was reported that aminophylline administration significantly increased the amount of fetal lung phospholipid in rabbits and rats, but it had no effect on the surfactant system $(7,8,20,21)$. In this study, we did not find any correlation between cord blood theophylline levels and the need for resuscitation at birth or need of mechanical ventilation in the first 48 hours, regardless of the presence or not of RDS and apnea. We thought that they had no effect on the respiratory system, as theophylline levels in the cord blood were fairly low, and the effects of methylxanthines are identified in pharmacological doses.

Based on the results of this study, we did not find any correlation between the cord theophylline levels and early pulmonary morbidities in premature infants. Although the theophylline levels that were measured in the cord blood were much lower than therapeutic serum levels, we concluded that the cord theophylline level is not valuable as a prognostic factor for pulmonary morbidities in premature newborns. Further experimental studies are needed to determine the levels of theophylline that provides fetal lung maturation.

:Acknowledgement: The authors would like to thank Anll Dolgun for statistical analysis.

Conflict of interests: The authors have no conflicts of interest relevant to this article.

Financial Disclosure: The authors have no financial relationship relevant to this article to disclose.

Informed Consent: Obtained.

\section{References}

1. Adén U. Methylxanthines during pregnancy and early postnatal life. Handb Exp Pharmacol. 2011;(200):373-89.

2. Grosso LM, Bracken MB. Caffeine metabolism, genetics, and perinatal outcomes: a review of exposure assessment considerations during pregnancy. Ann Epidemiol. 2005; 15(6):460-6.

3. Durrant KL. Known and hidden sources of caffeine in drug, food, and natural products. J Am Pharm Assoc (Wash). 2002(4);42:625-37.

4. Frary CD, Johnson RK, Wang MQ. Food sources and intakes of caffeine in the diets of persons in the United States. J Am Diet Assoc 2005;105(1):110-3.

5. Grosso LM, Triche E, Benowitz NL, Bracken MB. Prenatal caffeine assessment: fetal and maternal biomarkers or self-reported intake? Ann Epidemiol. 2008;18(3): 172-8.

6. Grosso LM, Triche EW, Belanger K, Benowitz NL, Holford TR, Bracken MB. Caffeine metabolites in umbilical cord blood, cytochrome P-450 1A2 activity, and intrauterine growth restriction. Am J Epidemiol. 2006; 163(11):1035-41.
7. Okumura M, Tsuruoka M, Isohama Y, Kai H, Takahama $\mathrm{K}$, Miyata T. Effects of xanthine derivatives on phosphatidylcholine secretion in primary culture of rat type II pneumocytes. Jpn J Pharmacol. 1995;67(2):165-8.

8. Landers S, Corbet A, Cregan J, Frink J, Rudolph AJ. Effect of aminophylline and caffeine on total and surfactant phospholipid in fetal rabbit lung. Am Rev Respir Dis. 1984;130(2):204-8

9. Browne ML. Maternal exposure to caffeine and risk of congenital anomalies: a systematic review. Epidemiology 2006;17(3):324-331.

10. Schatz M, Dombrowski MP, Wise R, Momirova V, Landon $\mathrm{M}$, Mabie W, et al. The relationship of asthma medication use to perinatal outcomes. J Allergy Clin Immunol. 2004;113(6):1040-50.

11. Godel JC, Pabst HF, Hodges PE, Johnson KE, Froese GJ, Joffres MR. Smoking and caffeine and alcohol intake during pregnancy in a northern population: effect on fetal growth. CMAJ. 1992;147(2):181-8.

12. Klebanoff MA, Levine RJ, DerSimonian R, Clemens JD, Wilkins DG. Maternal serum paraxanthine, a caffeine metabolite, and the risk of spontaneous abortion. N Engl J Med. 1999;341(22):1639-44.

13. Cnattingius S, Signorello LB, Annerén G, Clausson B, Ekbom A, Ljunger E, et al. Caffeine intake and the risk of first-trimester spontaneous abortion. N Engl J Med. 2000; 343(25):1839-45.

14. Wen W, Shu XO, Jacobs DR Jr, Brown JE. The associations of maternal caffeine consumption and nausea with spontaneous abortion. Epidemiology. 2001;12(1):38-42.

15. Bracken MB, Triche EW, Belanger K, Hellenbrand K, Leaderer BP. Association of maternal caffeine consumption with decrements in fetal growth. Am J Epidemiol. 2003;157(5):456-66.

16. Klebanoff MA, Levine RJ, Clemens JD, Wilkins DG. Maternal serum caffeine metabolites and small-for-gestational age birth. Am J Epidemiol. 2002;155(1):32-7.

17. Vlajinac HD, Petrović RR, Marinković JM, Sipetić SB, Adanja BJ. Effect of caffeine intake during pregnancy on birth weight. Am J Epidemiol. 1997;145(4): 335-8.

18. CARE Study Group. Maternal caffeine intake during pregnancy and risk of fetal growth restriction: a large prospective observational study. BMJ. 2008;337:a2332.

19. Wisborg K, Kesmodel U, Bech BH, Hedegaard M, Henriksen TB. Maternal consumption of coffee during pregnancy and stillbirth and infant death in first year of life: prospective study. BMJ. 2003;326(7386):420.

20. Moya FR, Gross I. Influence of theophylline on fetal rat lung phosphatidylcholine synthesis in vivo. Dev Pharmacol Ther. 1985;8(1):9-16.

21. Ekelund L, Burgoyne R, Brymer D, Enhörning G. Pulmonary surfactant release in fetal rabbits as affected by terbutaline and aminophyllin. Scand J Clin Lab Invest. 1981;41(3):237-45 